\title{
The Probability Approach to English If-conditional Sentences
}

\author{
Mei Wu \\ Assistant Professor, College of Foreign Languages, Leshan Normal University, China \\ E-mail: wmayline@yahoo.com \& wmayline@gmail.com
}

Received: January 20, 2012

Accepted: February 14, 2012

Published: May 1, 2012

doi:10.5539/elt.v5n5p37

URL: http://dx.doi.org/10.5539/elt.v5n5p37

\begin{abstract}
Users of the Probability Approach choose the right one from four basic types of conditional sentences-factual, predictive, hypothetical and counterfactual conditionals, by judging how likely (i.e. the probability) the event in the result-clause will take place when the condition in the if-clause is met. Thirty-three students from the experimental class received a 30-minute lecture on the Probability Approach between taking two conditional quizzes while 32 students from the control class did not. Averagely speaking, students who learned the Probability Approach were found to have scored 6 points higher in the second quiz than in the first quiz, compared with those who didn't learn this approach. This finding proved that the Probability Approach was effective in helping students acquire the four basic types of conditional sentences.
\end{abstract}

Keywords: Probability Approach, Factual conditionals, Predictive conditionals, Hypothetical conditionals, Counterfactual conditionals

\section{Introduction}

Teaching English conditionals has always been a difficult task for English teachers. There's no agreed-upon method of teaching English conditionals so far. Some teachers teach conditional sentences and subjunctive mood side by side, some teachers teach them separately, and teachers use different ways to classify conditional sentences.

I have tried various methods to teach English if-conditional sentences to freshman English majors, whose native language is Chinese, over the years. From my teaching experiences I have become aware of the need to simplify the classification of conditionals to only four basic types and to explain conditionals in a logical, self-explanatory manner.

I name my approach to teaching English conditionals the Probability Approach, because users of this approach firstly judge how likely (i.e. the probability) the event in the result-clause will take place when the condition in the if-clause is met, then chose the corresponding conditional sentence type based on the probability. To examine how effective this Probability Approach is, I conducted an empirical study using the classic controlled experimental design on 33 students from the experimental class and 32 students from the control class. The students in the experimental class received a 30-minute lecture on the Probability Approach between taking two conditional quizzes while the students in the control class did not. If students from the experimental class, who received the lecture on the Probability Approach, showed greater improvement in scores in the second conditional quiz than in the first conditional quiz, compared with students from the control class, the Probability Approach would be proven effective in enhancing students' understanding of the English conditionals.

Before we get to the specifics of the empirical study, let's review the types of English if-conditional sentences, the traditional methods for teaching English conditionals, as well as the Probability Approach that is under study in this paper.

\section{Literature Review}

\subsection{Overview of English If-conditional Sentences}

A typical English if-conditional sentence is "If $p$, then $q$ ". The if-clause (If-C) is the antecedent, in which the speaker states the condition of reasoning, and the then-clause (result-C) is the consequent in which the speaker states the outcome of inferences (Traugott et al., 1986:5).

English conditional sentences can be divided into sentences of real conditions and sentences of unreal conditions. The real conditionals can be further divided into those that express some type of factual relationship and those that present a predictive relationship. The unreal conditionals are used to express extremely unlikely or hypothetical situations and situations that are assumed to be contrary to known facts or counterfactual (Zhang, 2005:10-11). The 
following table (see Table 1) includes sample sentences of real or unreal conditions.

As varied as the types of conditional sentences are, the English conditionals are further complicated by the use of backshifting of tense. Comrie (1986) defines the backshifting of tense as "the use of a morphologically past tense with present (or future) time reference and of pluperfect with past time reference." For example, the present tense is used to refer to the future in the if-clause of future real conditional sentences (e.g. If I have time, I will study English.); the past tense is used in the hypothetical conditional to represent improbability in the present or future (e.g. If I had time, I would study English.); and the past perfect tense is used in the counterfactual conditional to refer to impossible events that didn't happen in the past (e.g. If I had had time, I would have studied English.) .

\subsection{Teaching English If-conditional Sentences to Chinese Students}

Conditional sentences ranked fifth on a list of most serious teaching problems encountered by ESL teachers, according to a survey conducted in Los Angeles area (Covitt, 1976). Teaching if-conditional sentences to Chinese students is particularly hard because of the negative transfer of Chinese on students' acquisition of English conditionals.

The Chinese language has only one verb-tense pattern, so Chinese speakers do not change tenses and modality in the verb phrase to indicate whether the conditional sentence is factual, hypothetical or counterfactual (Zhang, 2005:18). Instead, Chinese makes use of the context, time reference and internal semantic logic to differentiate the conditional types (Wu, 1994). As a result, the English real conditional sentences with normal time reference and thus similar to corresponding Chinese conditionals are comparatively easy for Chinese learners to acquire. However, the English unreal conditional sentences, involving a backshifting of tense, are challenging for Chinese learners.

Chinese teachers have been trying various methods of teaching English conditionals to Chinese students. Shang Mingkui (1989: 34-37) and Ding Wangdao (1979: 58-60) proposed teaching methods that are based on a comprehensive listing of possible combinations of an if-clause and a result-clause. Ouyang Zhiding (2009: 61-65) put forward a tabular method to summarize and contrast the subjunctive forms in tables. Zhao Xiuzhen (1996: 48-50) proposed teaching three most common types of English conditionals, namely, the predictive, hypothetical and counterfactual conditionals. She left out the present factual conditionals. Zhang Bin's empirical study involving 70 Chinese college students from Hunan University of Science and Technology also discovered that even though the present factual was expected to be the easiest type to acquire, "quite a lot of participants mistook present factual conditionals as predictive conditionals, and the evidence was that they added modal will in the main clause of the present factual conditionals" (2005: 66-67). The studies conducted by Zhao Xiuzhen (1996: 48-50) and Zhang Bin (2005: 66-67) prove that the present factual conditional sentences have been traditionally overlooked in many ESL/EFL textbooks and in English teaching practice despite of the high frequency of the present factual conditionals in everyday English.

Based on the analysis above, I propose teaching four basic types of English conditionals to students. These four types are: the factual conditional sentences, the predictive conditional sentences, the hypothetical conditional sentences, and the counterfactual conditional sentences (Zhang, 2005: 9-14; Liu, 2011: 16-24). I also propose teaching English conditionals separately from the subjunctive mood. In addition, I propose making the backshifting of tense readily understandable by listing four types of conditionals according to their probability of realizing the event in the result-clause. I name this approach to English conditionals the Probability Approach.

\subsection{The Probability Approach to English If-conditional Sentences}

Users of the Probability Approach to four basic types of English if-conditional sentences look at how likely (i.e. the probability) the event in the result-clause will take place when the condition in the if-clause is met. By this method, the English if-conditional sentences can be loosely classified into four groups: the factual conditionals, the predictive conditionals, the hypothetical conditionals and the counterfactual conditionals.

In the factual conditionals (i.e. the zero conditionals), the event in the result-clause is bound to happen as long as the condition in the if-clause is met (probability $=100 \%$ ).

In the predictive conditionals (i.e. the first conditionals), the event in the result-clause is highly likely to happen in the future, as long as the condition in the if-clause is met (probability $\approx 50 \%$ ).

In the hypothetical conditionals (i.e. the second conditionals), the event in the result-clause is unlikely yet possible to happen when the condition in the if-clause is met (probability $\approx 10 \%$ ). The hypothetical conditionals are usually used to express wishes and desires that are unlikely to be realized.

In the counterfactual conditionals (i.e. the third conditionals), the event in the result-clause is assumed to take place or become true when the situation in the if-clause, which is known to be impossible in the past, is met (probability = 
$0 \%)$.

The following table (see Table 2) includes these four basic types of conditional sentences in the order of high-to-low probability.

It's worth noting that these four basic types of conditionals and their structures are not the only way, nor the "correct" way, of dealing with their corresponding conditions. The verb phrase patterns in the if-clause and the result-clause can refer to different or unrelated time frame, respectively. This kind of conditional sentences are called Mixed Conditionals. Let's look at the following two examples of mixed conditionals:

[Example 1] If only the patient had received a different treatment instead of using the antibiotics he might still be alive now.

\section{[Example 2] Had Judy been more careful on the math exam, she would get much better results now.}

In the two examples above, the if-clauses refer to the situations that are assumed not to have taken place or not to be true. For example, "if only the patient had received a different treatment instead of using the antibiotics" in the first example indicates that the patient actually used the antibiotics and did not receive a different treatment. In a similar manner, "had Judy been more careful on the math exam" in the second example indicates that Judy in reality were not careful on the math exam.

Even with if-clauses that resemble those in the counterfactual conditionals, these two examples do not indicate impossibility in the past, as the result-clauses refer to imaginary results that are contrary to the known facts at present. For example, "he might still be alive now" in the first example indicates that he is no longer alive. In a similar manner, "she would get much better results now" in the second example indicates that her grades are far from being satisfactory at present.

Despite that the mixed conditionals mentioned above and other colloquial, dialectal or sub-standard conditional expressions are perhaps more true to the language as it is used, I still propose teaching the four basic types of conditionals to beginner learners of English conditionals, as these four types are simplified representation of English conditionals in real life.

\section{Methodology}

\subsection{Research Questions and Hypotheses}

This research aims to investigate how effective the Probability Approach is in teaching English if-conditional sentences using a classic controlled experimental design.

Research Question 1. Do research subjects from both the experimental class and the control class show improvement in their understanding of the English if-conditional sentences over time, as indicated by the differences of their scores from conditional quiz I and conditional quiz II?

Hypothesis I: The research subjects from both the experimental class and the control class would show improvement in their understanding of the English if-conditional sentences over time, as averagely speaking, they would score higher in the second conditional quiz than in the first conditional quiz.

Research Question 2. Is the Probability Approach effective in teaching students the English if-conditional sentences, as indicated by the degrees of improvement in scores from two conditional quizzes, for research subjects who received a 30-minute lecture on the Probability Approach and those who did not receive the lecture?

Hypothesis II. The research subjects from the experimental class, who received a 30-minute lecture on the Probability Approach to the English if-conditional sentences, averagely speaking, would show greater improvement in scores from the first and the second conditional quizzes, than research subjects from the control class, who did not receive the lecture.

\subsection{Research Instrument}

Research subjects completed two blank-filling conditional quizzes (see Appendix). There were a total of 19 questions in the first conditional quiz and 14 questions in the second conditional quiz. In every question, blank spaces took the place of the missing verb phrases, and before each blank space the basic form of a target verb was given in parentheses. Each blank weighed two points. The total score for each test was calculated using the following formula:

Total score $=100-$ number of mistakes $x 2$

The conditional quizzes were developed in a way that the different types of conditionals were arranged randomly. It's worth noting that question 3, 4, 5, 13, and 19 in the first conditional quiz were tested again in the second 
conditional quiz.

\subsection{Research Procedures}

Sixty-five freshman English majors from two classes in a teachers college in Sichuan completed the first conditional quiz outside of the class. Afterwards, the experimental class $(\mathrm{N}=33)$ received a 30 -minute lecture on the Probability Approach. From this lecture, the students from the experimental class learned how to decide upon a conditional sentence type by judging the probability of realizing the condition in the result-clause. The control class $(\mathrm{N}=32)$, however, did not receive the lecture. The students from the control class were merely given the answers to test questions. These students also discussed with their teacher the questions they didn't get right, but they were not introduced to the Probability Approach.

Sixty-five students from both classes took a second conditional quiz after a week.

I collected test scores for all research subjects in two conditional quizzes, entered and analyzed the data using SPSS 13.0. I also used a two-tailed paired samples $t$ test to compare the mean scores from two quizzes.

\subsection{Research Subjects}

Sixty-five freshman English majors from two classes in a teachers college in Sichuan completed the two conditional quizzes. One hundred and thirty scores from the two conditional quizzes by the experimental class $(\mathrm{N}=33)$ and the control class $(\mathrm{N}=32)$ were collected.

The research subjects in both classes were overwhelmingly female (females: $60,92 \%$; males: $5,8 \%$ ), and this is typical of an English Education program in a teachers college in Sichuan, where these young girls are trained to be city or country primary/middle school English teachers.

\section{Results and Discussion}

Hypothesis I predicted that research subjects, with or without receiving a 30-minute lecture on the Probability Approach to the English conditionals, would score higher in the second conditional quiz than in the first conditional quiz. A two-tailed paired samples $t$ test was conducted to compare the mean scores in the first conditional quiz and in the second conditional quiz. For research subjects from the experimental class, who received the Probability Approach lecture, there was a significant difference in the mean scores from the first conditional quiz ( $\mathrm{M}=53.64$, $\mathrm{SD}=13.9)$ and those from the second conditional quiz $(\mathrm{M}=84.48, \mathrm{SD}=6.4) ; t(32)=-12.814, p<0.001$. For research subjects from the control class, who did not receive the lecture, there was also a significant difference in the mean scores from the first conditional quiz $(\mathrm{M}=59.19, \mathrm{SD}=10.9)$ and those from the second conditional quiz ( $\mathrm{M}=84$, $\mathrm{SD}=6.7) ; t(31)=-12.584, p<0.001$ (see Table 3 ).

Hypothesis II predicted that research subjects who received a 30-minute lecture on the Probability Approach to the English conditionals would show greater improvement in scores from the first and the second conditional quizzes, than research subjects who did not receive the lecture. The results of a two-tailed paired samples $t$ test supported Hypothesis II as well. Even though research subjects from both classes scored higher in the second conditional quiz than in the first conditional quiz, students from the experimental class who received the lecture showed greater improvement in scores than those from the control class, who didn't receive the lecture. Averagely speaking, research subjects who didn't receive the lecture increased their scores by 24.81 points (from a mean score of 59.19 to a mean score of 84), and those who received the lecture increased their scores by 30.36 points (from a mean score of 53.64 to a mean score of 84.48). The difference of 6 points $(=30.36-24.81)$ is attributable to the lecture on the Probability Approach to the English conditionals (see Table 3). In another word, the Probability Approach was proven to be effective in enhancing students' understanding of the English conditionals.

Even though the research results support both of the initial hypotheses, this empirical study has some limitations. First of all, there is a significant but low correlation between the test scores from the first conditional quiz and those from the second conditional quiz for all research subjects, $r(64)=.314, \mathrm{p}<.05$. The statistical significance for correlations depends upon two factors - the correlation coefficient and the number of cases $(\mathrm{N})$. As $\mathrm{N}$ increases, the size of the correlation coefficient needed to be statistically significant decreases (Moore, Burnett \& Moore, 1986:19). With a relatively large $\mathrm{N}(\mathrm{N}=64)$, this low correlation coefficient $(r=.314)$ is of little practical value. In another word, we can't say that students who did well in the first conditional quiz also did well in the second conditional quiz. So there's no way to know whether these two quizzes were equally difficult. In addition to that, five questions that had been tested in the first conditional quiz were tested again in the second conditional quiz. The repetitive testing of these five questions may have somewhat contributed to the improvement in scores. Second, both the experimental class and the control class are disproportionally female. It would be great if the sample were more balanced in terms of gender. 


\section{Conclusion}

This empirical study involving 65 freshman English majors in a teachers college in Sichuan used the classic controlled experimental design. Thirty-three students from the experimental class, after receiving a 30-minute lecture on the Probability Approach to English if-conditionals, averagely speaking, scored 6 points higher in the second conditional quiz than in the first conditional quiz, compared with 32 students from the control class, who didn't receive the lecture. This finding proved that it was effective to teach students how to understand four basic types of conditionals - factual, predictive, hypothetical and counterfactual conditionals, by looking at their probability of realizing the event in the result-clause.

The Probability Approach simplifies the multiple types of English if-conditionals and presents the four basic types of conditionals in a logical, therefore readily understandable, fashion. This approach is particularly helpful for beginner Chinese learners of English conditionals, because it makes it easy to judge which type of conditionals to use.

Of course, "it would seem to be both more efficient in terms of language learning, and more true to the language as it is used, to expose students to as many examples as possible of real non-past conditionals, involving the full range of possible combinations, rather than to try to place them in some sort of structural straitjacket" (Maule, 1988: 119).

\section{References}

Comrie, B. (1986). Conditionals: A Typology. In Traugott, E. C., Meulen, A., Reilly, J. S. \& Ferguson, C. A. (Eds), On Conditionals. Cambridge: Cambridge University Press.

Covitt, R. (1976). Some Problematic Grammar Areas for ESL Teachers. MA Thesis. University of California, Los Angeles.

Ding, Wangdao. (1979). On Teaching English Conditionals and Subjunctive Mood. Foreign Languages Teaching and Research, 17(1), 58-60.

Liu, Hsiu-hui. (2011). Second Language Acquisition of If-conditionals in English. MA Thesis. National Taiwan Normal University.

Maule, D. (1988). "Sorry, but if He Comes, I Go": Teaching Conditionals. ELT Journal, 42(2), 117-123.

Moore, G. E., Burnett, M. F., \& Moore, B. A. (1986). Approved Practices in Reporting Quantitative Research. Journal of Vocational Education Research, 11(4), 1-24.

Ouyang, Zhiding. (2009). A Shortcut to Teaching Subjunctive Mood: A Tabular Contrast Approach. Crazy English (Teachers' Version), (4), 61-65.

Shang, Mingkui. (1989). On Tenses in English Conditionals. Foreign Languages Research, 6, 34-37.

Traugott, E. C., Meulen, A., Reilly, J. S., \& Ferguson, C. A. (Eds). (1986). On Conditionals. Cambridge: Cambridge University. http://dx.doi.org/10.1017/CBO9780511753466

Wu, H. F. (1994). "If Triangle Were Circles,..."-A Study of Counterfactuals in Chinese and in English. Taipei: Crane Publishing.

Zhang, Bin. (2005). A Study of the Acquisition of English If-conditional Sentences by Chinese Learners. MA Thesis. PLA University.

Zhao, Xiuzhen. (1996). On Three Commonly-seen Basic English Conditionals. Journal of Anshan Normal College (Synthetic), 1, 48-50.

\section{Author}

Mei Wu (Assistant Professor)

Academic title/degree: Master of Science in Applied Communication Research from College of Communication, Boston University, MA, USA

Working place: College of Foreign Languages, Leshan Normal University, P.R.C.

Research field: Teaching English as a Foreign Language, Literature in English Language 
Table 1. Types of English if-conditional sentences listed by tense

\begin{tabular}{ll}
\hline Present Real Conditional & Present Unreal Conditional \\
If I have time, I study English. & If I had time, I would study English. \\
(Sometimes I have time.) & (I don't have time.) \\
\hline Past Real Conditional & Past Unreal Conditional \\
If I had time, I studied English. & If I had had time, I would have studied English. \\
(Sometimes I had time.) & (I didn't have time.) \\
\hline Future Real Conditional & Future Unreal Conditional \\
If I have time, I am going to/will study. & If I had time, I would study English. \\
(I don't know if I will have time or not.) & (I won't have time.) \\
\hline
\end{tabular}

Table 2. Types of English if-conditional sentences listed by probability

\begin{tabular}{|c|c|c|c|c|c|}
\hline Types & $\%$ & $\begin{array}{l}\text { Answer a } \\
\text { question like ... }\end{array}$ & Example & Structure & $\begin{array}{l}\text { Time } \\
\text { reference }\end{array}$ \\
\hline $\begin{array}{l}\text { Factual conditionals } \\
\text { /Zero conditionals }\end{array}$ & $100 \%$ & $\begin{array}{l}\text { What happens } \\
\text { if...? }\end{array}$ & If you heat ice, it melts. & $\begin{array}{l}\text { If }+ \text { present simple } \rightarrow \\
\text { present simple }\end{array}$ & anytime \\
\hline $\begin{array}{l}\text { Predictive conditionals } \\
\text { /First conditionals (Type I) }\end{array}$ & $50 \%$ & $\begin{array}{l}\text { What will } \\
\text { happen if...? }\end{array}$ & $\begin{array}{l}\text { If it rains, I will stay at } \\
\text { home. }\end{array}$ & $\begin{array}{l}\text { If }+ \text { present simple } \rightarrow \\
\text { will+verb }\end{array}$ & future \\
\hline $\begin{array}{l}\text { Hypothetical conditionals } \\
\text { /Second conditionals (Type } \\
\text { II) }\end{array}$ & $10 \%$ & $\begin{array}{l}\text { What would } \\
\text { happen if...? }\end{array}$ & $\begin{array}{l}\text { If I won the lottery, I } \\
\text { would buy a car. }\end{array}$ & $\begin{array}{l}\text { If }+ \text { past simple } \rightarrow \\
\text { would }+ \text { verb }\end{array}$ & $\begin{array}{l}\text { Present or } \\
\text { future }\end{array}$ \\
\hline $\begin{array}{l}\text { Counterfactual conditionals } \\
\text { /Third conditionals (Type III) }\end{array}$ & $0 \%$ & $\begin{array}{l}\text { What would } \\
\text { have happened } \\
\text { if...? }\end{array}$ & $\begin{array}{l}\text { If I had won the lottery, I } \\
\text { would have bought a car. }\end{array}$ & $\begin{array}{l}\text { If }+ \text { past perfect } \rightarrow \\
\text { would have+past } \\
\text { participle }\end{array}$ & past \\
\hline
\end{tabular}

Table 3. Results of a paired samples $t$ test for comparing score means in conditional quizzes

\begin{tabular}{|c|c|c|c|c|}
\hline \multirow{3}{*}{ Mean } & \multicolumn{2}{|c|}{ Control Class } & \multicolumn{2}{|c|}{ Experimental Class } \\
\hline & Quiz I & Quiz II & Quiz I & Quiz II \\
\hline & $\begin{array}{c}53.64 \\
(13.932)\end{array}$ & $\begin{array}{c}84.48 \\
(6.404)\end{array}$ & $\begin{array}{c}59.19 \\
(10.929)\end{array}$ & $\begin{array}{c}84 \\
(6.696)\end{array}$ \\
\hline $\mathrm{N}$ & \multicolumn{2}{|c|}{32} & \multicolumn{2}{|c|}{33} \\
\hline Df & \multicolumn{2}{|c|}{31} & \multicolumn{2}{|c|}{32} \\
\hline$t$ & \multicolumn{2}{|c|}{-12.584} & \multicolumn{2}{|c|}{-12.814} \\
\hline
\end{tabular}

Note: $p=.000$. Standard Deviations appear in parentheses below means.

\section{Appendix: Conditional Quiz I}

1. She hates TV. She thinks television is a waste of time. (If/When)_ If she watches any television at all, it is usually a documentary or a news program.

2. My friend always keeps in touch by mail. (If/When)_When I get a letter, I usually write back immediately.

3. If I (have)_ had enough money, I (go)_ would go _on safari to Kenya. However, my bank account is empty!

4. I love to travel! When I (have)_ have enough money, I (go)__ go abroad. I do it almost every year.

5. I really wanted to go on safari to Kenya with my friends, but I couldn't afford to go. If I (have) had had enough money, I (go)_ would have gone with them.

6. I'm sorry, I didn't know you were allergic to chocolate. If I (know)_ had known, I (make)__ would have made you a vanilla birthday cake.

7. Stop asking me what Amanda bought you for Christmas. Even if I (know)_ knew what she bought you, I (tell, not)_ wouldn't tell you.

8. Nobody here speaks English. Too bad Gloria isn't here. If she (be)__were with us, she (can)__ could act as our interpreter.

9. I am afraid I won't be able to come to your wedding next week because my company is sending me to New York to attend a trade show. I (miss, never)__ would never miss your wedding if I 
(have) had a choice in the matter.

10. If the weather is nice tomorrow, she (walk)__ will walk_ along the river to school.

11. If you were to help me move tomorrow, I (treat)__ would treat you to a dinner and a movie.

12. If I were in Tahiti right now, I (snorkel)_ would be snorkeling along a beautiful reef. I wouldn't be stuck here in this office with mountains of paperwork.

13. If Jerry hadn't stopped to pick up that quarter, he (cross)__ would have been crossing the street when the bus ran the red light. He might have been killed!

14. Tina's train arrived ahead of schedule. If I hadn't decided to go to the train station early, she (wait)__would have been waiting there for more than twenty minutes before I arrived.

15. If I (pass)_ had passed the test, I (get)__ will get_ an "A" in the class. Instead, I got a "C." I really should have studied more.

16. If I (be)_ were_rich, I (buy)_ would have bought_ that new Mercedes we saw yesterday. Unfortunately, I can't even afford a used car.

17. We (go)_ would go _ skiing this weekend, but there's no snow. Oh, well! We will just have to find something else to do instead.

18. If Heather spoke Chinese, she (translate)__ would have translated_the email for you yesterday.

19. Clarence: Mary, have you ever had a teacher who changed your life or influenced you greatly?

Mary: Yes. But the teacher influenced me in a very negative way. I have always had problems with math, and I think it comes from my seventh grade math teacher, Mr. Harris. He thought girls couldn't do math. When any girl (ask) asked a question, he always (sigh)_ sighed and (say)_ said _, "Girls can't do math. It's a well known fact." When a boy (ask)__asked__a question, he (smile)__smiled_and (ask)_ asked for his answer.

Clarence: That's terrible! Your teacher actually said that to you?

Mary: Yes. If he ever did let me answer a question, and I actually got it right, he always (say)_ said_ that it was a lucky guess.

Clarence: Your parents (should, do)_should have done_something about him. They (could, go)_could have gone to the principle of the school and complained about the way Mr. Harris treated the girls. If you (be)_ were my child, I (demand)_ would have demanded that such an irresponsible teacher be fired.

Mary: You're right! If somebody (force) had forced_Mr. Harris to treat the children equally, I (become) would have become more confident in math. His behavior (might, affect)_ might have affected every girl in that class.

Clarence: It might have. I'm glad our children don't have teachers like that!

\section{Appendix: Conditional Quiz II}

1. All of us would have enjoyed the party much more if there_C quite such a crowd of people there.
A. weren't
B. hasn't been
C. hadn't been
D. wouldn't been

2. A for the fact that she broke her leg, she might have passed the exam.
A. Had it not been
B. Hadn't it been
D. Was it not
D. Were it not

3. D if I had arrived yesterday without letting you know beforehand?
A. Would you be surprised
B. Were you surprised
D. Had you been surprised
D. Would you have been surprised

4. If you explained the situation to your solicitor, he A able to advise you much better than I can.
A. would be
B. will have been
D. Was
D. Were

5. If only I_ B _ play the guitar as well as you!
A. would
B. could
D. should
D. might

6. "You__ D borrow my notes provided you take care of them," I told my friend.
A. could
B. should
D. must
D. can

7. If only the patient_ D a different treatment instead of using the antibiotics he might still be alive now.
A. had received
B. received
D. should receive
D. were receiving

8. Had Judy been more careful on the math exam, she_D_much better results now.
A. would be getting
B. could have got
D. must get
D. would get 
9. If I (have) _had_enough money, I (go)_ would go_ on safari to Kenya. However, my bank account is empty!

10. I love to travel! When I (have)_ have enough money, I (go)__ go _ abroad. I do it almost every year.

11. I really wanted to go on safari to Kenya with my friends, but I couldn't afford to go. If I (have) had had enough money, I (go)__would have gone with them.

12. If Jerry hadn't stopped to pick up that quarter, he (cross)_would have been crossing the street when the bus ran the red light. He might have been killed!

13. Tina's train arrived ahead of schedule. If I hadn't decided to go to the train station early, she (wait)_ would have been waiting there for more than twenty minutes before I arrived.

14. Clarence: Mary, have you ever had a teacher who changed your life or influenced you greatly?

Mary: Yes. But the teacher influenced me in a very negative way. I have always had problems with math, and I think it comes from my seventh grade math teacher, Mr. Harris. He thought girls couldn't do math. When any girl (ask) asked a question, he always (sigh)_ sighed and (say)__ said _ "Girls can't do math. It's a well known fact." When a boy (ask)_ asked__a question, he (smile)_ smiled_and (ask)_asked for his answer.

Clarence: That's terrible! Your teacher actually said that to you?

Mary: Yes. If he ever did let me answer a question, and I actually got it right, he always (say)__said__that it was a lucky guess.

Clarence: Your parents (should, do)_ should have done_something about him. They (could, go)__could have gone to the principle of the school and complained about the way Mr. Harris treated the girls. If you (be)__ were my child, I (demand)_ would have demanded that such an irresponsible teacher be fired.

Mary: You're right! If somebody (force) _ had forced_Mr. Harris to treat the children equally, I (become) would have become more confident in math. His behavior (might, affect)_ might have affected_every girl in that class.

Clarence: It might have. I'm glad our children don't have teachers like that! 